\title{
Survival and death from subdural haematoma on medical wards
}

\author{
M. W. DRONFIELD \\ M.B., M.R.C.P.
}

\author{
G. M. MEAD \\ M.B., M.R.C.P.
}

\author{
M. J. S. LANGMAN \\ M.D., F.R.C.P.
}

City Hospital, Nottingham

\begin{abstract}
Summary
All patients with subdural haematoma presenting to medical wards in Nottingham over a 5-year period have been reviewed. Of twenty-one such patients eight were first diagnosed at post-mortem, whilst all of the remaining thirteen patients in whom the diagnosis was made in life survived following neurosurgical evacuation of the haematoma.

Diagnostic failure was caused mainly by failure to consider the possibility of subdural haematoma or misinterpretation of negative investigations. An attempt has been made to characterize the clinical patterns that may suggest the presence of a subdural haematoma, and recommendations are made on the investigation of such patients.
\end{abstract}

\section{Introduction}

Subdural haematoma (SDH) is a relatively common condition. Its particular importance is that correctly diagnosed and treated, prognosis is excellent; missed diagnosis often results in death. Previous reports about such patients have come from neurosurgical centres (McKissock, Richardson and Bloom, 1960; Walker, Espir and Shephard, 1968) where the suspicion of neurosurgical disease is high and diagnostic techniques are well developed. However, it is to the general medical wards that most of these patients are first referred. The present authors have, therefore, reviewed retrospectively the case notes of all patients in the Nottingham area who developed SDH, and were admitted to medical wards over a 5-year period. This included patients in whom the diagnosis was first made at autopsy.

\section{Patients and methods \\ Patients}

The Nottingham area (population 730,000 ) is served by two district general hospitals to which all medical emergencies are admitted. The neurosurgi-

Correspondence: Dr M. W. Dronfield, Department of Therapeutics, City Hospital, Nottingham NG5 1PB. cal service is situated at Derby Royal Infirmary 17 miles away, and no patients from Nottingham are admitted there without prior admission in Nottingham. The authors reviewed retrospectively the case notes of all patients admitted to medical wards in whom a diagnosis of SDH was made between January 1970 and December 1974; cases admitted as acute head injury to surgical and other wards were not included.

Twenty-one patients were found to have had SDH, in the years studied, and their details are shown in Tables 1 and 2. In thirteen patients the diagnosis was made during life, and all of these survived (Table 2), the remaining eight patients being first diagnosed at post-mortem (Table 1). Fourteen of the patients were men, and seven, women; ages ranging from 49 to 81 years (mean age 66 years).

\section{History}

Headache was a prominent symptom in eleven patients, but the most striking feature in the history of all the patients was the disturbance of conscious level, of which some of the patients were aware and which was obvious in all cases to the medical attendants. History was, therefore, often difficult to obtain and admission usually followed deterioration in the patient's general condition.

\section{Predisposing factors}

A clear history of an episode of head injury was found in ten patients (see Tables 1 and 2), indeed two patients had attended a casualty department and had normal skull X-ray examinations, but in none of the patients did the head injury lead to loss of consciousness. The interval between trauma and admission varied from $24 \mathrm{hr}$ to 6 months. A further four patients had histories of falls, often multiple, without an identifiable episode of skull trauma. In two patients SDH developed whilst receiving anticoagulant treatment, and in both instances the thrombotest was considerably prolonged and outside the therapeutic range. Both these patients were in hospital when 
TABLE 1. Patients who died

\begin{tabular}{|c|c|c|c|c|c|c|c|c|c|}
\hline \multirow{2}{*}{$\begin{array}{c}\text { Patient } \\
\text { No. }\end{array}$} & \multirow[b]{2}{*}{ Sex } & \multirow{2}{*}{$\begin{array}{c}\text { Age } \\
\text { (years) }\end{array}$} & \multirow{2}{*}{$\begin{array}{l}\text { Days from } \\
\text { admission } \\
\text { to death }\end{array}$} & \multirow[b]{2}{*}{ Site* } & \multirow[b]{2}{*}{ Head injury† } & \multirow[b]{2}{*}{ Clinical diagnosis } & \multicolumn{3}{|c|}{ Investigations $\ddagger$} \\
\hline & & & & & & & Echo & Scan & C.S.F. \\
\hline 1 & $\mathbf{M}$ & 76 & 6 & $\mathbf{R}$ & Doubtful & Cerebro-vascular disease & nd & nd & Normal \\
\hline 2 & $\mathbf{M}$ & 76 & 14 & $\mathbf{L}$ & Doubtful & Not stated & nd & nd & Normal \\
\hline 3 & $\mathbf{M}$ & 68 & 20 & $\mathbf{R}$ & Doubtful & Carcinomatosis & nd & nd & nd \\
\hline 4 & $\mathbf{F}$ & 59 & 4 & $\mathbf{R}$ & Doubtful & Encephalitis & nd & nd & $\begin{array}{c}\text { Xanthochromia } \\
15 \text { lymphocytes/ } \\
\mathrm{mm}^{3}\end{array}$ \\
\hline 5 & $\mathbf{F}$ & 77 & 5 & B & $\begin{array}{l}\text { Yes ( } 5 \text { days) } \\
\text { (anticoagulants) }\end{array}$ & Cerebro-vascular accident & Normal & nd & nd \\
\hline 6 & $\mathbf{F}$ & 81 & 6 & B & Yes (6 months) & Cerebro-vascular accident & Normal & $\begin{array}{r}\text { Normal } \\
\text { (gamma) }\end{array}$ & nd \\
\hline 7 & $\mathbf{F}$ & 66 & 17 & $\mathbf{L}$ & No & $\begin{array}{l}\text { Expanding intracerebral } \\
\text { haemorrhage }\end{array}$ & nd & nd & Normal \\
\hline 8 & $\mathbf{F}$ & 74 & 2 & B & No & Hypothermia & nd & nd & nd \\
\hline
\end{tabular}

* R, Right; L, left; B, bilateral.

$\dagger$ Interval from head injury to admission in brackets.

$\ddagger$ nd, Not done.

TABLE 2. Patients who survived

\begin{tabular}{|c|c|c|c|c|c|c|c|c|}
\hline \multirow{2}{*}{$\begin{array}{l}\text { Patient } \\
\text { No. }\end{array}$} & \multirow[b]{2}{*}{ Sex } & \multirow[b]{2}{*}{ Age } & \multirow{2}{*}{$\begin{array}{l}\text { Days from } \\
\text { admission } \\
\text { to diagnosis }\end{array}$} & \multirow[b]{2}{*}{ Site* } & \multirow[b]{2}{*}{ Head injury $\dagger$} & \multicolumn{3}{|c|}{ Investigationsf } \\
\hline & & & & & & Echo & Scan§ & C.S.F. \\
\hline 9 & $\mathbf{M}$ & 80 & 18 & B & Yes (1 week) & nd & $\begin{array}{c}\text { L.SDH } \\
\text { (gamma) }\end{array}$ & Normal \\
\hline 10 & $\mathbf{M}$ & 57 & 1 & $\mathbf{L}$ & Yes ( 3 months) & nd & nd & nd \\
\hline 11 & $\mathbf{M}$ & 73 & 2 & B & Yes (6 weeks) & nd & R.SDH & nd \\
\hline 12 & $\mathbf{M}$ & 49 & 10 & $\mathrm{~L}$ & Yes (2 months) & nd & L.SDH & Normal \\
\hline 13 & $\mathbf{M}$ & 76 & 11 & $\mathbf{R}$ & Yes ( 10 days) & Shift to $L$. & R.SDH & Xanthochromia \\
\hline 14 & $\mathbf{M}$ & 49 & 7 & $\mathbf{R}$ & No (anticoagulants) & nd & nd & nd \\
\hline 15 & $\mathbf{M}$ & 60 & 23 & B & Yes (2 months) & nd & L.SDH & nd \\
\hline 16 & $\mathrm{~F}$ & 60 & 6 & B & No & nd & nd & Protein $0.8 \mathrm{~g} / 1$ \\
\hline 17 & $\mathbf{M}$ & 66 & 3 & $\mathbf{L}$ & No & nd & nd & nd \\
\hline 18 & $\mathbf{M}$ & 61 & 1 & $\mathbf{R}$ & No & nd & normal & nd \\
\hline 19 & $\mathbf{M}$ & 58 & 17 & $\mathbf{L}$ & Yes ( 1 day) & nd & normal & $\begin{array}{c}\text { Blood-stained } \\
\text { xanthochromia }\end{array}$ \\
\hline 20 & $\mathbf{M}$ & 57 & 12 & $\mathbf{L}$ & Doubtful & nd & normal & Xanthochromia \\
\hline 21 & $\mathrm{~F}$ & 67 & 16 & $\mathbf{R}$ & No & Shift to L. & $\begin{array}{l}\text { R. Cerebral } \\
\text { infarct }\end{array}$ & nd \\
\hline
\end{tabular}

* R, Right; L, left; B, bilateral.

$\dagger$ Interval from head injury to admission in brackets.

$\ddagger$ nd, Not done.

$\S$ L.SDH, Left subdural haematoma; R.SDH, right subdural haematoma.

TABLE 3. Summary of clinical signs

\begin{tabular}{lclr}
\hline Impaired conscious level: & $21 / 21$ & Focal neurological signs: & $19 / 21$ \\
\hline Subsequent alteration of conscious level: & 3 & Hemiparesis & 13 \\
Fluctuating & 4 & Bilateral extensor plantar responses & 7 \\
Gradual deterioration & 3 & Early papilloedema & 3 \\
Rapid deterioration & 2 & Homonymous hemianopia & 2 \\
Gradual improvement & 9 & Pupillary inequality & 2 \\
No change noted & & Extensor plantar response alone & 1 \\
\hline
\end{tabular}


they developed SDH, one sustaining a head injury during the admission, and it was notable that neurological deterioration occurred very rapidly in both patients. The remaining six patients had no identifiable predisposing factors.

\section{Examination}

Only one patient had clinical evidence of skull trauma-a frontal bruise first noted at post-mortem (patient 8). Depression of conscious level, which is a classical feature of SDH, was present in all twentyone of the patients, and the subsequent patterns of alteration of conscious level are shown in Table 3.

Nineteen of the twenty-one patients were found to have focal neurological signs at some time, as shown in Table 3, hemiparesis being the most commonly found abnormality occurring in thirteen patients. This was almost invariably mild, although in two patients (nos 2 and 21) complete hemiplegias did develop. The hemipareses were contralateral to the SDH in all cases except patient 12. Four of the patients with hemipareses had bilateral SDH.

In addition to a hemiparesis, two patients (nos 14 and 21) had homonymous hemianopia and three had bilateral extensor plantar responses. In patient 19 the only focal neurological sign was an extensor plantar response, whilst in a further four patients, only one of whom had bilateral SDH, extensor plantar responses and brisk tendon jerks were the only findings. Early papilloedema was noted in three patients and in patient 16 the sole abnormal signs were pupillary inequality and paralysis of conjugate upward deviation of the eyes. There were no focal neurological signs in patients 4 and 8 .

\section{Investigations}

Investigative facilities outside neurosurgical units are limited, and none of the patients had carotid angiography or skull burr holes made before transfer to the regional neurosurgical centre. Investigations performed in Nottingham are detailed in Tables 1 and 2.

\section{Skull X-ray}

Thirteen patients had a skull X-ray performed, one of which was abnormal (patient 19) showing a pineal shift which was subsequently shown to be away from the side of the SDH. No skull fractures were found.

\section{Lumbar puncture}

This was performed in ten patients. Abnormalities were found in five of these, four of whom had xanthochromic cerebrospinal fluid. In addition to this, one sample was uniformly blood-stained and one contained 15 lymphocytes $/ \mathrm{ml}$. In a further patient the only abnormality was a protein level of $0 \cdot 8 \mathrm{~g} / \mathrm{l}$.

\section{Echoencephalogram}

Only four patients underwent this investigation. In two of these a definite shift of the mid-line was demonstrated away from the side of SDH. In a further two patients no shift of the mid-line was demonstrated, both these patients being subsequently found to have bilateral SDH.

\section{Brain scan}

Rectilinear scans were performed in seven patients, four of which showed changes which were considered diagnostic of SDH, whilst two were normal and one was interpreted as showing a right cerebral infarction. Two of the three gamma camera scans were normal, the third showing an SDH. In three of the four negative scans the haematomas were subsequently found to be unilateral.

\section{Electroencephalogram}

This provided no useful information in the two patients (1 and 19) in whom it was performed.

\section{Outcome}

Eight patients died (mean age 72 years) and thirteen patients recovered (mean age 63 years). All of the latter group were treated by neurosurgical evacuation of the SDH, eleven patients recovering completely, whilst two have residual dementia.

In none of the eight patients who died was the correct diagnosis made in life. The diagnoses appearing on the death certificates were cerebrovascular accident in three patients, and one each of hypothermia, carcinomatosis and bronchopneumonia. In the two remaining patients diagnostic uncertainty led to referral to the district coroner. The diagnosis of SDH in these patients was missed for a variety of reasons. In patients 5 and 6 , the possibility of SDH was raised but was thought to be excluded by a normal echoencephalogram in both patients, and a normal brain scan in patient 6 ; both of these patients had bilateral lesions. In the remaining six patients the diagnosis was not considered. In patient 3 this was due to therapeutic nihilism-he had coexisting carcinomatosis. In none of these six patients was there a history of head injury, in striking contrast to the patients in whom the diagnosis was considered in life, of whom nine of the fifteen gave a definite history of head injury.

The number of days between the admission of the patient and diagnosis or death (see Tables 1 and 2) varied from 1 to 23 days (mean $9 \cdot 5$ days), there being no difference between those being successfully diagnosed and treated and those who died.

\section{Discussion}

Previous series of SDH have been from neurosurgical centres and by implication the diagnosis has 
been made successfully in life. The authors were able to discover a disturbing number of cases in whom the diagnosis was made after death and they believe that death certificate diagnoses such as 'cerebrovascular accident' may conceal more cases, as $40 \%$ of patients dying in hospital in Nottingham do not have post-mortems. This series demonstrates again that advanced age is no bar to good results after clot evacuation. The problem lies in identifying the group of patients who might benefit from further investigation and selecting appropriate techniques (preferably non-invasive) with acceptable false-positive and false-negative results.

Such patient identification relies predominantly on the recognition of clinical patterns. It is well known that a history of head injury followed by headache and deterioration in conscious level are cardinal features of the condition. Most of the patients in this study in whom the diagnosis was made in life gave a clear history of previous head injury in contrast to patients in whom the diagnosis was not made, and it seems that the history of a head injury was a useful clue to the diagnosis in many cases. Detailed histories, however, were not usually available from the patients because of the impairment of conscious level that was invariably present, and the importance is stressed of making every effort to obtain a history from relatives or friends. Despite this impairment of conscious level more than $50 \%$ of the patients complained of headache, eight from the surviving group and three of the patients who died. Headache has been noted to be a prominent complaint in well over $50 \%$ of the patients in other series (McKissock et al., 1960; Walker et al., 1968), and its presence in the appropriate clinical setting is another useful pointer to the diagnosis. When examining the patient, particular regard should be paid to focal neurological signs which were almost always present in the patients in this study, most commonly in the form of a hemiparesis-these were strikingly mild when compared with the impairment of conscious level, which was often progressive and sometimes fluctuating.

Investigations in a large group of potential cases need to be simple and widely available. Skull X-ray may show bony fractures or pineal shift-it is a simple, worthwhile investigation, although the diagnostic yield is low. Lumbar puncture does not contribute specific diagnostic information, but may be useful in excluding other conditions, e.g. meningitis; and xanthochromic fluid may be found indicating intracranial haemorrhage. Echoencephalography is a rapid, simple investigation. A positive result (a shift of mid-line structures) should lead to further confirmatory investigation, although negative results should not lead to rejection of the diagnosis as up to $30 \%$ of SDHs are bilateral and thus unlikely to produce a shift (McKissock et al., 1960;
Hurwitz, Halpern and Leopold, 1974). Brain scanning with technetium has been found useful in SDH (Hurwitz et al., 1974; Gilday, Coates and Golden- $c .$. berg, 1973), but of the seven patients in the present series in whom this technique was used only four revealed the lesion. False-positives may also occuro but their cause, such as scalp wounds or previous neurosurgery, is usually obvious. Eventual diagnosis $\frac{\bar{c}}{\vec{D}}$ usually depends on carotid angiography or explora- $\stackrel{\varpi}{\varrho}$ tory skull blurr holes. Carotid angiography has a morbidity of its own (Perrett and Nishoka, 1966), particularly in the elderly, and therefore the diagno-웅 sis is often made with skull burr holes. It must be $\vec{\omega}$ accepted that a number of such investigations will prove negative if missed diagnoses are to be avoided. 0

The role of investigation outside neurosurgical 3 . units is probably limited. In patients in whom there is a sufficiently strong clinical suspicion of $\mathrm{SDH}, \dot{\sigma}$ immediate transfer to the neurosurgical centre would $\vec{\sigma}$ seem the most appropriate action. Usually, however, of the picture will be less clear, and the authors would o then suggest that skull X-ray, echoencephalogram? and brain scan be done, remembering that all three $\rightarrow$ investigations will be negative in a significant pro- $\frac{\mathbb{O}}{O}$ portion of patients. Recently the EMI scanner has $\frac{2}{2}$ been shown to be extremely accurate in diagnosing SDH (Ambrose, 1973; Paxton and Ambrose, 1974, $\overrightarrow{0}$ but facilities for its use are likely to remain limite outside specialist centres.

\section{Acknowledgments}

We are most grateful to the physicians of the City and $\frac{2}{D}$ General Hospitals, Nottingham, for permission to report $\stackrel{1}{2}$ patients under their care, and to Mr Julian Taylor of Derby $\overrightarrow{\vec{\sigma}}$ Royal Infirmary, for help in tracing patients.

\section{References}

Ambrose, J. (1973) Computerized transverse axial scanning (tomography): Part 2. Clinical application. British Journal of Radiology, 46, 1023.

Gilday, D.L., Coates, G. \& Goldenberg, D. (1973) Subdural haematoma-what is the role of brain scanning in its diagnosis? Journal of Nuclear Medicine, 14, 283.

Hurwitz, S.R., Halpern, S.E. \& Leopold, G. (1974) Brain scans and echoencephalography in the diagnosis of chronic subdural haematoma. Journal of Neurosurgery, 40, 347.

McKissock, W., Richardson, A. \& Bloom, W.H. (1960) 을 Subdural haematoma. A review of 389 cases. Lancet, i, $\mathrm{N}$
1365 .

Paxton, R. \& Ambrose, J. (1974) The EMI scanner. A brief $\mathrm{N}$ review of the first 650 patients. British Journal of Radiology, S
47,530 .

Perrett, G. \& Nishioka, H. (1966) Report on the co-opera- $\sigma$ tive study of intracranial aneurysms and subarachnoid haemorrhage. IV. Cerebral angiography. An analysis of carotid and vertebral angiography in 5,484 patients. Journal of Neurosurgery, 25, 98.

Walker, M.E., Espir, M. \& Shephard, R.H. (1968) Sub- $\square$ dural haematoma: presentation and diagnosis on medical $\bar{O}$ wards. Postgraduate Medical Journal, 44, 785. 